\title{
Notas Editoriais
}

\section{AURELIO RIBEIRO LEITE DE OLIVEIRA ${ }^{1}$ e FABRÍCIO SIMEONI DE SOUSA ${ }^{2}$}

A diversidade dos trabalhos submetidos à TEMA sempre é motivo de destaque nas edições da revista. Nesta primeira edição de 2016, contamos com a publicação de oito artigos, distribuídos em diversas áreas, tais como Teoria de Filas, Controle, Redes, Solução Numérica de Equações Diferenciais, Sistemas Dinâmicos e Otimização.

Os dois primeiros artigos tratam de aplicações de métodos matemáticos e estatísticos no estudo e projeto de redes sem fio, cada vez mais presentes na nossa sociedade. Uma aplicação de Cadeias de Markov na análise de redes sem fio pode ser vista no artigo "Estimação de probabilidade de transbordo do buffer em redes OFDM-TDMA utilizando Cadeias de Markov e Curva de Serviço". Outra abordagem para o projeto de redes sem fio é apresentada no artigo "Uma abordagem híbrida GRASP-ILS para o problema de projeto de redes com topologia anel-estrela".

Temos três contribuições na área de desenvolvimento e análise de métodos numéricos para solução de EDP's. O artigo “Adaptividade e estimativas de erro orientadas por metas aplicadas a um benchmark test de propagação de onda" traz avanços em métodos adaptativos de elementos finitos para a equação da onda. Uma contribuição na área de escoamentos em meios porosos pode ser vista no artigo "Utilização de modelos autoregressivos na quantificação de incertezas em problemas de transporte linear", tratando o problema através de equações estocásticas e quantificação de incertezas. Outro artigo nessa área traz contribuições na paralelização de métodos de diferenças finitas para a equação de Maxwell, usando programação em GPU, intitulado "Melhorando o desempenho computacional de um esquema de diferenças finitas para as equações de Maxwell".

O tópico de sistemas dinâmicos está de volta às páginas da TEMA com o artigo "Bifurcações sela-nó da região de estabilidade de sistemas dinâmicos autônomos não lineares", trazendo contribuições na análise de estabilidade de tais sistemas. Já o artigo "On the existence of solutions for optimal control problems on time scales" versa sobre a existência de soluções ótimas para sistemas de controle, abordando o problema das escalas de tempo.

Fechando esta edição da revista, destacamos o trabalho "Joint approximate diagonalization of symmetric real matrices of order 2", que traz contribuições para a diagonalização de matrizes simétricas, com aplicações em otimização.

\footnotetext{
${ }^{1}$ Universidade Estadual de Campinas - UNICAMP, SP, Brasil. E-mail: aurelio@ ime.unicamp.br

${ }^{2}$ Universidade de São Paulo - USP, São Carlos, SP, Brasil. E-mail: fsimeoni@icmc.usp.br
} 
Não deixe de citar os artigos da TEMA em seus trabalhos de pesquisa. Isto aumentará a credibilidade de nosso periódico.

Boa leitura. 